\title{
Diferenciar, redistribuir, reconhecer: ensaio de atualização dos debates sobre terra e educação para quilombos
}

\author{
José Maurício Arruti
}

\section{Reconhecendo}

É muito recente o reconhecimento de comunidades negras rurais no Brasil. Evidentemente sempre se soube da grande parcela de população negra que compóe o campesinato e o proletariado rural brasileiro, mas isso nunca, até meados da década passada, conferiu particularidade a essa população, seja diante da história, da militância ou das políticas públicas. A mobilização negra urbana não só foi a garantia de uma visibilidade para a questão desde as primeiras décadas do século XX, como acabou tendo um efeito de contraluz sobre a população rural. Da mesma forma, uma abordagem da questáo fundiária centrada na economia e na dinâmica da luta de classes excluíra qualquer consideração sobre as diferenças socioculturais internas ao campesinato. Finalmente, a noção de comunidade, tendo sido praticamente abandonada no vocabulário sociológico a partir da década de 1960, passa a ser agenciada pela militância católica como produto (e projeto) da combinação entre cristianismo primitivo e comunismo, gerando uma imagem homogênea, igualitarista e cristã desta população. Impedimentos epistemológicos à emergência da diferença que funda a noção de comunidades negras rurais. Dois processos de desenvolvimento paralelo, cuja comunicação ainda está por ser avaliada e interpretada, ofereceram elementos novos a este contexto, permitindo emergir a diferença.
O avanço nos estudos antropológicos sobre o campesinato brasileiro "de fronteira" e a retomada do debate sobre a reforma agrária da Nova República, abrem espaço para que certas particularidades da posse da terra entre as populações do Norte e Nordeste do país se tornassem não só visíveis, como social e politicamente significativas. Chamou-se a atenção para a existência de inúmeras situações em que o campesinato se organizava de forma distinta daquela que orientou a militância política do campo até então, fosse ela católica ou comunista. Descobriu-se que a demanda de diversos destes grupos não se adequava ao modelo dos assentamentos de reforma agrária, baseados no parcelamento individualizado da terra, tendo em vista a constituição de pequenos proprietários independentes.

A soma destas situações permitiu reconhecer a existência das terras de uso comum, isto é, área apossada de forma indivisa por um grupo de famílias ligadas entre si por estreitos laços de filiação e aliança. Acrescente-se que os limites físicos destas terras tendem a se confundir com os limites sociais e mesmo histórico-memoriais de uma determinada comunidade, na medida em que tal conjunto de famílias se pensa e age como um grupo social dotado de uma identidade própria, vinculadas a sistemas simbólicos particulares e a regras de acesso e uso das terras de uso comum. Boa parte destas comunidades atenderiam às designações que também indicariam o modo de constituição dos seus 
territórios, tais como terras de preto, terras de herança, terras da santa, entre outras, às quais em geral acrescentam um topônimo ou um nome de família, de santo ou de ancestral.

Quase ao mesmo tempo, os desdobramentos da militância católica renovada pela Teologia da Libertação e pelos primeiros ecos de uma Teologia da Inculturação, atuante entre uma população negra recém migrada do campo para as capitais do Norte e Nordeste do país, abre espaço para uma militância negra de características distintas daquela que já havia ocupado o seu espaço nas capitais do Sul e do Sudeste. Neste caso, o discurso sobre o passado escravo e sobre a figura histórica dos quilombos não era mediada apenas pela metáfora política ou pela releitura crítica da história, mas por algumas horas de viagem de ônibus ou de barco, até a casa dos pais ou dos avós. $\mathrm{O}$ que era metáfora em um contexto converteu-se em re-ligação em outro. Em meados dos anos de 1980 estes jovens militantes negros iniciam, sob a observação ou com o apoio de alguns jovens sociólogos do campesinato de fronteira, encontros regionais de comunidades negras rurais, no Maranhão e em Belém.

Nenhum dos dois movimentos, porém, imprimiram, por si, mudanças na concepçáo dominante sobre o trato da questão agrária. Se, de um lado, o próprio projeto de Reforma Agrária ampla e democrática naufragou no momento de definição do novo texto constitucional de 1988, de outro, a adoção de medidas de reparação histórica e cultural dirigidas à população negra teve melhor aceitação na definição do texto constitucional. O revigoramento do movimento negro ao longo dos dez anos anteriores e os acúmulos da reflexão acadêmica sobre o caráter estrutural do racismo brasileiro se somariam ao impacto político imediato das comemoraçóes nacionais relativas ao centenário da Abolição.

Essa dualidade informou, naturalmente, o trato da questão negra no contexto de redação da Constituição de 1988: de um lado, o pleno reconhecimento do tema da cultura, impresso nos artigos 215 e 216 (Capítulo "Cultura") e, de outro, o reconhecimento mais do que sucinto, precário, e pensado como temporário, do tema da terra das comunidades negras, impresso no artigo 68 (parte anexa final, das "Disposições Transitórias”). Além disso, como este artigo fora formulado segundo a semântica do movimento negro urbano, para o qual a metáfora do quilombo ganhava centralidade e resumia o seu desconhecimento sobre a extensão da questão negra rural, a sua formulação escolhe falar em "remanescentes das comunidades de quilombo" em lugar de enunciar diretamente comunidades negras rurais.

Este estranhamento fez com que a utilidade do citado artigo constitucional para as demandas da população das terras de preto não fosse evocada senão alguns anos depois, em 1992, a partir dos conflitos vividos pelas comunidades de Frexal (MA) e de Rio das Rãs (BA). A partir daí, porém, feita tal conexão entre a demanda reprimida e a brecha legal no ordenamento constitucional, teria início um novo momento histórico para o debate sobre a "questão racial" no Brasil, no qual a população negra rural ganha grande visibilidade. Assim, ainda que as primeiras formulaçóes conceituais e a própria vanguarda do movimento quilombola tenha surgido nos estados ao norte do país, o fenômeno da auto-atribuição nestes termos se estendeu a todos os estados da federação, revelando a extensão que a questão negra rural alcançava. Foi o movimento social que, assim, revelou o quanto o fenômeno das terras de uso comum, originadas como "terras de preto", "terra de herdeiros", "terra de santa" e congêneres poderia ser generalizado para além das "situaçôes de fronteira agrícola”, cobrindo contextos e processos históricos muito diversos ao sul do país. A jovem militância quilombola que emerge em todo o país a partir destes novos direitos se faz 
herdeira, ao mesmo que transforma, portanto, uma luta que seus pais e avós travaram dentro dos sindicatos sob o rótulo genérico de posseiros ou trabalhadores rurais.

\section{Definindo direitos}

A primeira resposta do Estado brasileiro a essa nova realidade veio em 1995, na forma de uma portaria interna do INCRA, que determinava a medição, demarcação e titulação "mediante a concessão de título de reconhecimento, com cláusula 'pró-indiviso"” de áreas de comunidades remanescentes de quilombos localizadas em áreas públicas federais ou em áreas arrecadadas ou obtidas por processo de desapropriação, sob a jurisdição do órgão (INCRA/P/ no 307/95). A portaria tinha um alcance limitado porque elegia como beneficiárias apenas as comunidades situadas em terras públicas ou previamente desapropriadas, não prevendo mecanismos de desapropriação próprios, nem uma regulamentação interna, que só começaria a ser discutida em 1996. Essas discussóes, que eram para durar apenas 60 dias, se estenderam por quatro anos. No momento em que o debate alcançava o consenso necessário à nova redação do Projeto de Lei que regulamentasse os direitos quilombolas (a partir da proposição do PL 129/95), porém, o Governo Federal atravessaria o processo transferindo a competência da titulação de terras quilombolas para o Ministério da Cultura: todas as questóes relativas aos remanescentes de quilombos passavam a estar concentrada na Fundação Cultural Palmares (FCP).

Apesar desses impasses e nos estreitos limites da citada portaria, o INCRA titulou, apenas no Pará entre os anos de 1995 e 1998, sete terras de quilombos, contemplando cerca de 600 famílias. Nesses casos, prevaleceu a interpretação sobre a auto-aplicabilidade do "artigo
68" (tema ainda hoje controverso), assim como a concepção de que o reconhecimento desses grupos como remanescentes de quilombos dependia apenas da sua auto-atribuição, dispensando, com isso, a produção de laudos periciais comprobatórios, ao menos até que interesses conflitantes apresentassem contestação explícita da condição quilombola de alguma dessas comunidades.

As informaçôes sobre a responsabilidade das titulaçóes já efetuadas nem sempre ficam claras, dada a divergência entre diferentes documentos oficiais. Mas, segundo dados da FCP, entre 1998 e 2000, o órgão titulou onze terras de quilombos em parcerias celebradas com o INCRA ou com os Institutos de Terras Estaduais. Outras 18 terras foram tituladas por conta da própria FCP. Destas, apenas 12 tiveram seus títulos registrados, ou seja, foram efetivamente regularizadas. $\mathrm{O}$ processo de titulação oficial era tão precário e desinformado que nas outras seis comunidades o título emitido pelo Governo Federal seria recusado pelos cartórios por apresentarem sobreposição a outros títulos supostamente válidos sobre a mesma área. Nesses casos, os cartórios solicitam a "sustaçáo de dúvidas" e as comunidades pretensamente beneficiadas submergiram em uma longa indefinição que, em alguns casos, perdura até hoje, agravando ou mesmo abrindo situaçóes de conflito locais.

Em setembro de 2001, o Governo Federal atravessaria o processo mais uma vez, com a edição do Decreto Federal 3.912, que consolidaria a retirada de tais atribuiçóes do INCRA (agora as iniciativas do instituto seriam caracterizadas como improbidade administrativa), ao mesmo tempo em que interromperia o longo processo de debate sobre o Projeto de Lei destinado a regulamentar o artigo constitucional. $\mathrm{O}$ novo decreto recuava tanto na questão da auto-aplicabilidade do artigo 68, quanto na questão da auto-atribuição das comunidades. 
A situação só se alteraria em 2003, com a edição do novo decreto presidencial ( $\mathrm{n}^{\circ} 4.887$ ). $\mathrm{Na}$ ausência de legislação que regulamentasse o direito reconhecido na Constituição, mais de uma década depois de sua promulgação, a forma do decreto foi mais uma vez utilizada, mas agora pelo governo Lula. A novidade era que, enquanto o primeiro decreto buscava restringir a aplicabilidade dos direitos constitucionais quilombolas por meio de limitações formais e pela atribuição de responsabilidades fundiárias a uma fundação especializada na área cultural, este estabeleceu condições reais para o exercício de tais direitos, seguindo o acúmulo das discussóes travadas entre 1995 e 2000.

Com este decreto o Instituto Nacional de Colonização e Reforma Agrária (INCRA) passou a ser o responsável pelo processo de regularização fundiária das comunidades quilombolas; restituiu a possibilidade de se realizarem desapropriaçóes para este fim; incorporou o direito destas comunidades ao auto-reconhecimento, em concordância com a Convenção 169 da OIT e, finalmente, estabeleceu que a titulação das terras deve se dar em nome de entidade representativa da comunidade, em alternativa ao náo reconhecimento do ordenamento jurídico nacional das modalidades de uso comum típica das populaçóes tradicionais, entre elas as quilombolas.

\section{Definindo políticas}

A edição do decreto de 2003 viria acompanhada do reconhecimento destas comunidades em um sentido mais amplo, na medida em que as introduzia no rol de populaçóes atendidas por políticas diferenciadas, ao lado dos povos indígenas e das populaçóes tradicionais. Os documentos que pautaram a ação governamental neste sentido foram basicamente dois: o Programa Brasil Quilombola, criado em 2004, e a Agenda Social Quilombola, que organiza a pauta de iniciativas governamentais para o quadriênio de 2008-2011. A principal função destes dois grandes programas foi reunir sob uma mesma rubrica um conjunto de açóes e propostas dispersas por diversos ministérios e secretarias, dando-lhes não exatamente um sentido orgânico, mas, no máximo, coordenado. Isso acontece em função da opção fundamental de recusar uma tendência, que podia ser vista esboçada no governo anterior, de instituir o tema dos quilombos como assunto de um órgão, ministério, secretaria ou fundação, específico. Pelo contrário, as políticas para quilombos já surgem sob o signo da descentralização, que seria uma marca contemporânea até mesmo um campo que já foi tão centralizado como o indigenista.

O Programa Brasil Quilombola (PBQ) foi definido com base em seis objetivos gerais, que ajudavam a agrupar rubricas de diferentes políticas pré-existentes. Tais objetivos estavam voltados para a promoção de abordagens e mudanças de posturas internas às próprias comunidades atendidas: a promoçáo da agroecologia, de uma política de gênero e o estímulo ao protagonismo dos quilombolas em todos os processos de decisão, como forma de fortalecer sua identidade cultural e política. Os outros quatro objetivos do PBQ tinham a ver com mudanças de posturas e de abordagens internas ao próprio Estado nos diferentes níveis do poder executivo, tendo em vista o reconhecimento e o fortalecimento organizacional das comunidades de quilombos. Para isso, entravam em foco a própria elaboração e gestão das políticas públicas: o incentivo aos governos estaduais e municipais na promoção do acesso de quilombolas às políticas públicas, com ênfase na regularização da posse da terra e no estímulo ao desenvolvimento sustentável em seus territórios; a proposição de um modelo de gestão destas políticas que preserve a igual- 
dade de oportunidade dado à estas comunidades, em comparação com os demais públicos; a garantia dos direitos sociais e do acesso à rede de proteção social, com a exigência de uma articulação entre os diferentes órgãos governamentais com ações nas mais diferentes áreas.

O lançamento da Agenda Social Quilombola (ASQ), em 2007, implicou na definição de um conjunto de medidas bem mais específicas e setorizadas, quase sempre vinculadas aos pacotes de políticas desenhados pelo Programa de Aceleração do Crescimento (PAC). Tal vinculação é tão evidente em alguns setores que algumas destas políticas ganharam o rotulo de "PAC Quilombola", como aconteceu no caso das açóes do Ministério da Saúde voltadas ao saneamento.

Uma primeira observação a ser feita é relativa à mudança de postura do Estado brasileiro diante da questão quilombola: ela deixa de ser vista como tema exclusivamente cultural, para ser incorporada na larga variedade de políticas de responsabilidade pública. Até o decreto 4887/2003 e a definição do PBQ, foi o Ministério da Cultura que monopolizou as políticas para quilombos. A partir daí, é a Secretaria Especial de Políticas de Promoção da Igualdade Racial (SEPPIR), vinculada diretamente à Presidência da República, que ganha destaque como articuladora das ações distribuídas por diferentes ministérios, incluindo o remanejamento de recursos de programas sociais como o Bolsa Família, Fome Zero e Luz para Todos.

A segunda observação a ser feita é sobre a execuçáo orçamentária do PBQ, que tem ficado sempre muito aquém do previsto e prometido. As sucessivas análises realizadas pelo INESC (Instituto de Estudos Socioeconômicos) mostram que, entre 2004 e 2007 o programa gastou apenas $32,8 \%$ do seu orçamento. Uma terceira observação a ser feita, está relacionada à observação de um padrão mais largo. As "medidas estratégicas" que o governo prevê para efetuar as açóes planejadas para o $\mathrm{PBQ}$, por exemplo, são definidas como de "apoio" ao trabalho do Incra para regularização das terras quilombolas: formação de gestores públicos das áreas pertinentes à temática, na ampliação dos canais de interlocução com as representaçôes quilombolas, produção de informações qualificadas sobre tais comunidades e, finalmente, "direcionar as políticas universais para todas as comunidades quilombolas do país”. Esta última resume boa parte da concepçáo governamental sobre o tema: o reconhecimento dos quilombos como um segmento diferenciado da sociedade nacional náo leva de imediato a políticas diferenciadas. Pelo contrário, tal reconhecimento implica em um reforço e uma correção das políticas de redistribuição, na medida em que a diferença dos quilombos é traduzida em termos de um agravamento das condiçóes gerais da pobreza e não exatamente em demandas ou necessidades diferentes.

Isso permite afirmar que as políticas voltadas para comunidades quilombolas podem ser divididas, grosso modo, entre aquelas geradas especificamente para esta população e aquelas formuladas como simples extensão ou como atribuição de uma cota especial para esta população no interior de políticas universais ou focadas na pobreza. De um lado, há o reconhecimento de que o desrespeito histórico produzido pela escravidão e pela exclusão sistemática dos serviços e recursos disponibilizados pelo Estado Nacional deve levar a uma política de acesso diferenciado a tais recursos hoje, como forma de corrigir tal desrespeito histórico. Esta abordagem aproxima as políticas voltadas para a população quilombola das políticas voltadas para a populaçáo negra em geral. De outro lado, há uma segunda modalidade de reconhecimento, que corresponde ao reconhecimento não só da exclusão sistematicamente imposta pela fração politicamente dominante às demais parcelas da sociedade nacional, mas especifica- 
mente ao reconhecimento das formas próprias e distintas de organização social e cultural destas outras parcelas da sociedade nacional, que hoje tendem a ser designados também de forma particular. Neste segundo caso, o reconhecimento não pode ser reduzido à redistribuição, ainda que, evidentemente, a inclua. Esta segunda modalidade de reconhecimento implica em ultrapassar a visão do outro que o reduz apenas ao pobre, ao deficitário, ao dominado, para percebê-lo como efetivamente diferente. Em ambos os casos há algum reconhecimento e alguma redistribuição, mas no primeiro caso o reconhecimento resulta em uma política diferenciada, enquanto nos outros casos o reconhecimento gera um tratamento diferenciado no acesso a políticas indiferenciadas.

A seguir abordaremos o contexto atual em duas destas políticas: os embates em torno da política de terras (diferenciada) e os debates em torno da política de educação (em diferenciação).

\section{Território}

A retomada das açóes de regularização precisava ainda, porém, de uma normatização interna ao INCRA. Como o Instituto foi moldado aos objetivos de colonizar e promover uma reforma na distribuição de terras do país era necessário produzir ajustes em suas rotinas, critérios de produtividade e na própria cultura técnica e política dos seus funcionários. Ao lado da demarcação de terras destinadas à propriedade privada de famílias nucleares e cuja extensão são calculadas com base em critérios econômicos e agronômicos, o órgão deveria assumir a tarefa de demarcar territórios coletivos, cujos limites seriam estabelecidos por meio de critérios históricos e antropológicos, que levam em conta o modo tradicionalmente estabelecido de apropriação dos recursos naturais por parte destas comunidades.
A publicação destas novas Instruções Normativas (IN) só ocorreria em 2005, enquanto a contratação de antropólogos pelo INCRA, necessária à produção dos relatórios antropológicos de identificação territorial, só começaria em 2006. O resultado imediato disso, antes de qualquer regularização fundiária efetiva, foi uma forte mobilizaçáo contra os direitos quilombolas. Em meio a muitos debates e impasses, o governo teve que recuar na sua formulação inicial e publicar uma nova IN em 2007, que reproduzia, no plano técnico, o objetivo de limitar as ações de regularização desses territórios. Na negociação com a oposição ruralista, o governo aceitava alterar as normas internas ao INCRA em troca da suposta preservação do próprio decreto 4.788/2003.

Assim, o procedimento passou a contar com um maior número de etapas, que se iniciam com a produção do laudo antropológico de reconhecimento territorial, complementado com vários outros estudos técnicos, cujo resumo deve ser publicado no Diário Oficial da União. Depois disso, abre-se um período para a apresentação de contestaçóes ao relatório e, em seguida, mais uma dezena de etapas, até que, finalmente, a comunidade tenha o seu título de propriedade registrado em cartório. Um processo destinado a levar muitos anos.

A reação a tais mudanças foi grande por parte do movimento quilombola, mas também por parte dos estudiosos da questão e dos assessores das comunidades, além das entidades de apoio. Em resposta a tal reação o governo foi obrigado a realizar uma Consulta Nacional sobre o tema. A primeira iniciativa neste sentido se deu de forma improvisada, sem convocação oficial antecipada, lançando mão da presença de algumas lideranças quilombolas em Brasília por outros motivos. Há, porém, todo um debate relativo aos novos padrôes de tomada de decisão a que o governo brasileiro se comprometeu quando da assinatura de Convenções Internacionais como a da OIT, 
que exigem uma consulta efetiva às comunidades quando da elaboração de execução de políticas públicas que tenham efeitos sobre elas. Os procedimentos adotados na resposta a tais obrigaçóes devem ser considerados, portanto, como parte das próprias políticas públicas voltadas a tais populaçóes.

Informadas disso, as lideranças quilombolas se recusaram a legitimar a primeira iniciativa e propuseram transformar a Consulta Nacional em um processo amplamente informativo e participativo, que permitisse estabelecer um patamar mínimo de comunicação com o conjunto das comunidades quilombolas, informando-lhes sobre o objeto da consulta e colhendo delas as dúvidas, queixas, denúncias e sugestôes que devem informar os debates. A Advocacia Geral da União (AGU), porém, recusou a proposta e impôs um formato de consulta sucinto, no qual, apesar de não conseguir impor os pontos fundamentais de sua proposta de mudança às lideranças quilombolas, manteve-os em suspenso para que o presidente da república tomasse a decisão de tertius. Seis meses depois da Consulta, de fato, uma nova Instrução Normativa foi publicada com o mesmo texto que foi rejeitado pelos quilombolas e denunciado pelas organizações da sociedade civil.

Apesar disso, não se havia produzido qualquer garantia de que o decreto 4788/2003 não continuaria sendo questionado, conforme previsto no argumento que justificava a alteração da IN. A ação contra o decreto persistiu no STF. Apesar de a forma de decreto já ter sido utilizada antes pelo governo FHC (dec. 3.912/2001), a ADIN contra o Dec. 4.788/2003 usa justamente esta aparente irregularidade como argumento central para destituí-lo.

$\mathrm{O}$ atual quadro de titulaçóes de terras do INCRA é um efeito direto desta nova normativa. Apesar de existirem cerca de 600 processos de regularização de territórios quilombolas abertos, cerca de 380 deles só existem no papel, sem qualquer procedimento prático. No ano de 2008 o órgão publicou apenas 10 portarias de reconhecimento territorial, mas não titulou qualquer comunidade. As 23 terras quilombolas tituladas neste ano derivam de açôes dos institutos de terra dos estados do Pará, Piauí e Maranhão, contemplando as situaçóes em que as comunidades ocupavam terras devolutas ou do estado e, portanto, dispensavam a ação do INCRA. Em 2009, dos cinco títulos emitidos, quatro seriam de responsabilidade do INCRA, mas correspondiam a apenas duas comunidades do Rio Grande do Sul.

Este pobre desempenho, porém, foi suficiente para que uma ampla e intensa campanha contra os direitos territoriais quilombolas se articulasse em três frentes: na batalha pela opinião pública, assumida por setores hegemônicos da grande imprensa; na exclusão de definiçôes importantes para a garantia dos direitos quilombolas (como as de "território", “ocupação" e "autoatribuição") do texto final do Estatuto da Igualdade Racial; e no questionamento do decreto 4788/2003 no STF, por meio de uma ação do antigo PFL, atual DEM.

Reportagens em importantes jornais impressos e nos horários nobres do maior telejornal do país promoveram interpretações distorcidas e preconceituosas, veicularam informações falsas e alarmistas, com grande impacto sobre setores da administração pública e operadores da justiça. Diante do fato destes direitos estarem fundamentados tanto em amplos acordos, tratados e convençóes internacionais que apoiam e se somam ao processo de democratização da sociedade brasileira, quanto em pesquisas acadêmicas bem fundamentadas, o grande recurso passava a ser a retomada de antigas e sombrias mitologias, como a ameaça comunista, as ameaças de internacionalização da Amazônia, de segregação racial da população brasileira, do conluio internacional contra o desenvolvimento nacional. $\mathrm{E}$ houve casos em que, de fato, decisóes judiciais 
deixaram de lado os argumentos de direito e científicos para se basearem nestas reportagens e editoriais, travestidos de opinião pública, ainda que tais veículos não abram espaço para opiniôes contrárias.

Outro campo de disputas foram as negociações em torno do Estatuto da Igualdade Racial, no qual o governo (incluindo uma parcela do movimento negro) recuou sistematicamente em busca de acordos, visando o grande feito político que seria encerrar dez anos de espera pela aprovação do Estatuto. Os recuos, porém, mostraram-se excessivos, ineficazes e inglórios, sacrificando não apenas os direitos quilombolas, mas também outras causas do movimento negro, e produzindo um texto inexpressivo. A bancada ruralista impôs forte resistência em aprovar o texto do Estatuto se continuasse incluindo o artigo relativo à regularização dos territórios quilombolas em sua formulação alinhada ao decreto 4788/2003 - o que significaria converter o texto do decreto em texto de lei. Em resposta a isso, a SEPPIR negociou a eliminação do texto relativo aos direitos quilombolas, restringindo-se praticamente ao que já estava no texto da Constituição. Imaginava-se, então, que o relator do estatuto sacrificava os direitos quilombolas em nome de outros, como o das cotas. Porém, como já havia acontecido no caso da IN do INCRA, tal recuo não seria recompensado. Ao passar pelo Senado em junho de 2010, do texto do Estatuto seria extirpado também qualquer menção às cotas, da mesma forma que também foi excluída a previsão de políticas públicas voltadas para a saúde da população negra ${ }^{1}$.

\section{Educação}

O debate sobre educação quilombola tende a avançar nas duas direçôes em que a reforma educacional iniciada nos anos 1990 aponta. De um lado, para a inclusão das especificidades so- ciais e históricas das comunidades quilombolas entre os temas relativos à diversidade cultural adotados nos conteúdos curriculares em geral e, especificamente, daqueles estados e municípios nos quais tais comunidades existem, conforme diretriz exposta nos Parâmetros Curriculares Nacionais. De outro, com a discussão sobre a formulação de uma política educacional especificamente voltada para as comunidades quilombolas.

Mas, com relação a este último ponto, novamente, o que assistimos é o trânsito entre duas formas de se pensar tal atenção diferenciada: aquela que busca ampliar a rede até tais comunidades, assim como melhorar as condiçóes da rede de educação nestas comunidades, por exemplo, por meio do incremento simples do valor destinado a tais escolas (definido pelo FUNDEB com base no aumento do valor do repasse destinado de cada aluno das escolas quilombolas); e aquela que tende a falar em termos de uma "educação quilombola", ou seja, uma educação pensada a partir e para as especificidades socioculturais desta população. Uma educação diferenciada, a exemplo da Educação Indígena e da Educação do Campo.

As primeiras açóes governamentais para quilombos no campo educacional atuam pelo simples redirecionamento de uma parcela maior de recursos para as escolas que já atendem tais comunidades. Isso foi feito por meio do FUNDEB, que reparte o total das matrículas da educação básica presencial em subconjuntos que recebem diferentes índices de repasse das verbas do fundo segundo uma escala da ponderação. Como o Censo Escolar pergunta apenas se a escola é "localizada em área de remanescentes de quilombos", ele identifica escolas que são "quilombolas" apenas na medida em que estão localizadas em áreas identificadas como de comunidades remanescentes de quilombos, sem que isso implique a existência de qualquer diferenciação em sua forma físi- 
ca, métodos pedagógicos, gestão, composição e formação dos professores ou nos materiais didáticos utilizados. Além disso, tal classificação é atribuída no momento do preenchimento de formulário pelo diretor/a da escola, o que nos coloca o problema desta classificação não se dar nem por auto-atribuição da comunidade, nem pelo reconhecimento prévio e oficial desta comunidade e seu território pelo Estado brasileiro $^{2}$. Temos exemplos interessantes de como isso produz variaçóes importantes no computo geral, seja pela simples negação de que a escola seja quilombola, mesmo quando se trata de comunidade de notoriedade nacional, como acontece na Ilha da Marambaia (RJ), seja, ao contrário, quando tal classificação da escola ocorre sem ela encontre correspondência em uma comunidade quilombola.

A partir principalmente de 2010 , porém, o debate sobre Educação ganha novo rumo, na direção de configurar uma política efetivamente diferenciada. O Plano Nacional de Educação 2011-2020 tem como uma de suas novidades mais notáveis a incorporação de um capítulo sobre "Educação Quilombola”. O documento traz orientaçóes no sentido de que os poderes públicos elaborem um Plano Nacional de Educação Quilombola e uma legislação específica para o tema. Em ambos os casos, o foco deverá estar no direito à preservação de suas manifestaçôes culturais, na sustentabilidade de seu território tradicional, na observação de uma alimentação e de uma infraestrutura escolar que respeitem sua cultura e sua relação com o meio ambiente. Também está prevista formação diferenciada aos professores destas escolas, a criação de um programa de licenciatura quilombola e a elaboração de materiais didático-pedagógicos específicos. Enquanto no campo da gestão, recomenda-se a adoçáo de mecanismos que garantam a participação de representantes quilombolas na composição dos conselhos referentes à educação. Ainda que a situação de exclusão educacional destas comunidades seja grave, mesmo considerando apenas a oferta da escola universal, a elaboração de um Plano Nacional de Educação Quilombola aponta para o reconhecimento de que a abordagem do tema deve se dar a partir de uma perspectiva qualitativa, tendo em vista também a diferença e náo apenas a desigualdade no trato destas comunidades.

Assim, da mesma forma que no início dos debates sobre a definição dos direitos quilombolas à terra as opinióes oscilaram entre definir tais direitos como uma ampliação da reforma agrária ou como uma variação para negros de política indigenista, os atuais debates sobre educação para estas comunidades oscilam entre práticas que se limitam a aplicar a lei 10.639 (que estabelece a obrigatoriedade do ensino da História da África e da cultura afrobrasileira) e tendências que tendem a aproximar a educação quilombola ora de uma simples variação da "educação do campo", ora nos termos de uma educação diferenciada, como nos termos estabelecidos para a educação indígena. Mas, se no caso da terra, a política já se estabeleceu como propriamente diferenciada e vem sofrendo grandes resistências derivadas disso, no caso da educação o primeiro efeito da política de reconhecimento foi um efeito de redistribuição, que agora se vê diante dos dilemas da efetiva diferenciação: em que medida e que termos situar a diferença quilombola.

\section{Notas}

1. Coroando esta derrota do movimento social, o senador Demostenes Torres (DEM) pronunciou um discurso em plenário digno de um Eugène Terre'Blanche. O discurso do senador figurou no espaço público brasileiro como um sinal de que, diante da reação aos avanços do movimento social, todo um 
partido e uma parcela da imprensa assumem o racismo como uma posiçáo defensável. Observe-se como Demétrio Magnoli, colunista de alguns dos maiores jornais do país, saiu em defesa do senador contra os jornalistas que relataram o seu discurso com a justa surpresa que ele provoca em qualquer pessoa que se paute pelo respeito aos Direitos Humanos.

2. Aqui é necessário explicar que a Fundação Cultural Palmares, desde a edição do decreto 4887/2003, as- sumiu a atribuição de "certificar" as comunidades quilombolas por meio do seu registro em um livro de cadastro nacional. Tal certificação é baseada principalmente, mas não exclusivamente (para o bem e para o mal), na auto-atribuiçấo do grupo. É esta certificaçấo e este registro que levam à inclusão destas comunidades na lista das demais políticas públicas que dão atenção diferenciada a estas comunidades, como o Bolsa Família, por exemplo.

\section{autor \\ José Maurício Arruti \\ Professor do Departamento de Antropologia Social / Unicamp \\ Pós-Doutor em Antropologia Social / Cebrap}

Recebido em 13/10/2011

Aceito para publicação em 13/10/2011 